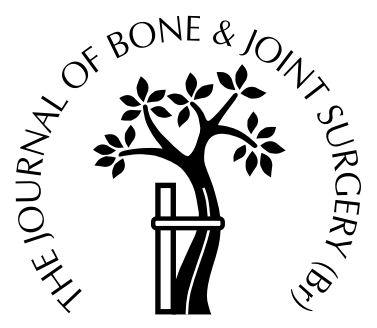

\title{
A simple method of shoulder arthrodesis
}

\author{
Nady Saleh El-Said Mohammed \\ From El-Minia University, Egypt
}

A new technique of shoulder fusion is presented using a posterior approach. After removal of the articular cartilage, a Rush pin is introduced from the spine of the scapula, through the glenoid into the medullary canal of the humerus. This is supplemented by tension-band wiring from the acromion to the neck of the humerus and a muscle pedicle graft attached to the acromion. A shoulder spica is applied for four to six weeks.

Four patients with injuries to the upper brachial plexus and 14 with paralysis of the upper arm due to anterior poliomyelitis have been followed for three years. One of the 18 patients developed nonunion; she had removed her own cast prematurely.

This method of fixation provides high shear resistance and low axial stiffness without deforming plastically. It does not affect bone growth in young patients, is effective in patients with osteoporosis, and gives a high rate of union.

J Bone Joint Surg [Br] 1998;80-B:620-3.

Received 2 September 1997; Accepted after revision 19 December 1997

Despite the recent interest in arthroplasty, many patients, especially in developing countries, are best served by an arthrodesis. Successful arthroplasty requires nearly normal functional anatomy, ${ }^{1}$ while the minimal requirement for shoulder arthrodesis is trapezius with strength graded as fair. $^{2}$

Arthrodesis of the shoulder has stood the test of time, mainly to improve upper-limb function after paralysis or to relieve pain in post-traumatic arthritis. ${ }^{3}$ Poliomyelitis is still common in some countries and remains the main indication for operation. ${ }^{4}$ Other paralytic conditions ${ }^{5,6}$ include injuries to the proximal brachial plexus, Erb's palsy, and traumatic paralysis of the deltoid. Arthrodesis of the shoulder may

N. S. E-S. Mohammed, MD, Assistant Professor of Orthopaedic Surgery Orthopaedic Surgery and Traumatology Department, El-Minia Medical College, El-Minia University, El-Minia, Egypt.

(C)1998 British Editorial Society of Bone and Joint Surgery 0301-620X/98/48330\$2.00 also be useful after the failure of shoulder arthroplasty, after unsuccessful operations for recurrent dislocation or massive rupture of the rotator cuff, or for severe infection. $^{1,5-8}$ It is the main salvage procedure when joint reconstruction or replacement is not available.

In paralytic conditions, the prerequisite is good function of the elbow and hand, ${ }^{3}$ although Seddon ${ }^{9}$ has shown that additional muscle transfers can provide useful elbow flexion in conjunction with shoulder arthrodesis. The operation should be simple and safe and provide a high rate of fusion. The method described has been developed with these principles in mind, and is applicable at all ages.

\section{Patients and Methods}

Arthrodesis of the glenohumeral joint was performed on 18 patients aged between nine and 54 years (mean 25). Three were repeat procedures, the original operation having failed to produce union.

Two repeat and 12 primary procedures were carried out in men, and one repeat and three primary operations in women. The right shoulder was affected in eight patients and the left in ten.

The indication for arthrodesis was paralysis of the upper arm secondary to anterior poliomyelitis in 14 patients and injuries of the upper brachial plexus in four. Six patients also had painful subluxation of the glenohumeral joint. The acromioclavicular and sternoclavicular joints were found to be normal in all 18 patients, and the nerve supply to trapezius and levator scapulae was intact in each, ensuring active abduction of the arm. The function of serratus anterior was also normal, but the rhomboids and pectoral muscles had varying grades of function. ${ }^{10}$ The distal joints of the affected arm were examined and hand function recorded. Only four patients with lesions of the brachial plexus had any weakness of the elbow.

Operative technique. The patient lies on the unaffected side. An incision is made along the spine of the scapula, over the acromion and along the lateral aspect of the shoulder (Fig. 1a). The spine of the scapula is exposed subperiosteally, avoiding the acromioclavicular joint; the distal acromion is partly divided with an osteotome and reflected downwards with the attached deltoid to act as a vascularised graft. The glenoid and proximal humerus are 
a

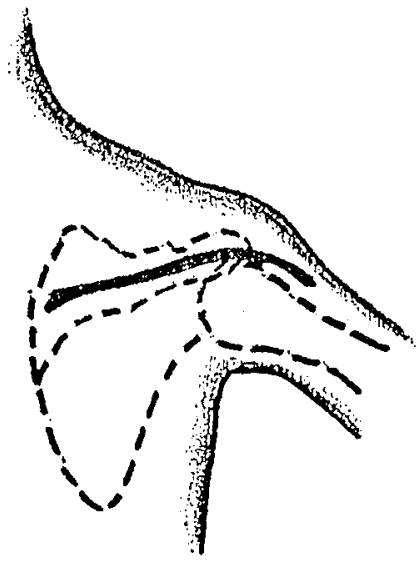

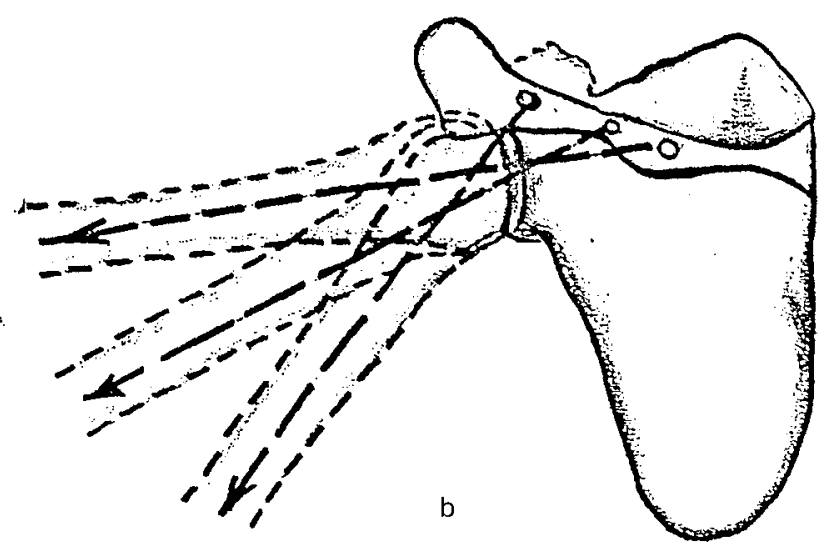
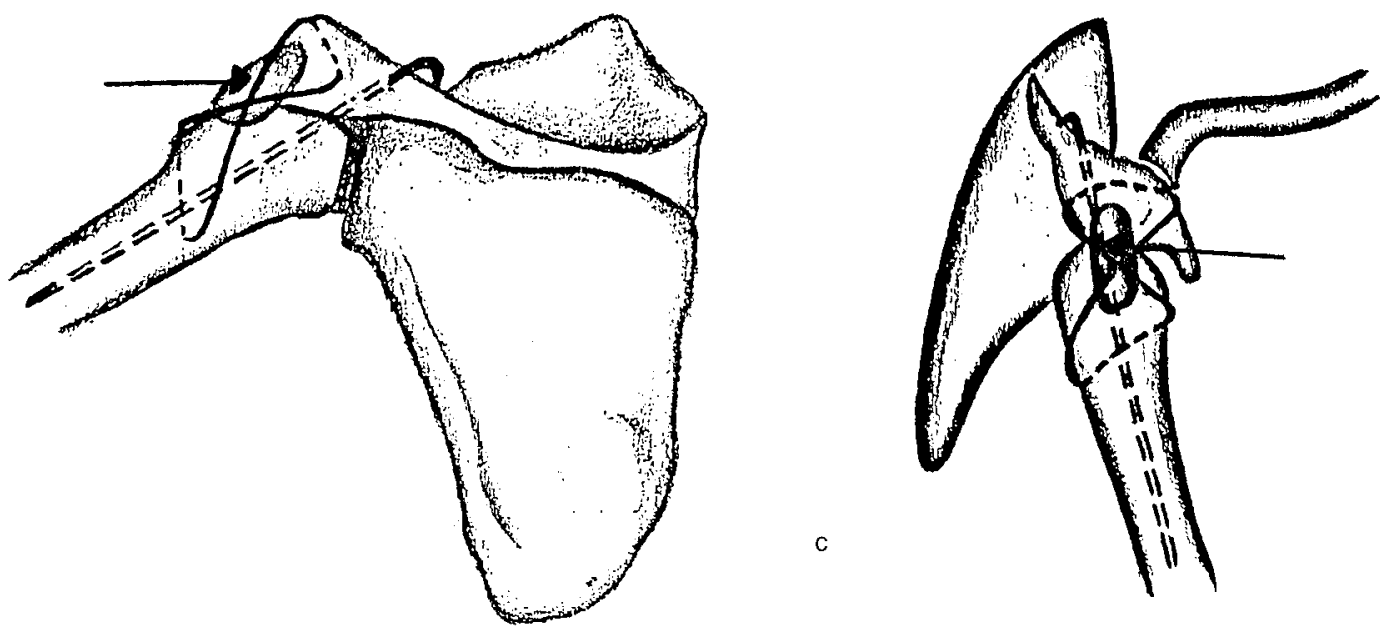

Fig. 1

Diagrams showing a) the skin incision, b) the differing point of entry in the spine of the scapula according to the degree of abduction and c) the completed procedure with a Rush pin, tension-band wiring and a muscle pedicle bone graft (arrow).

exposed and denuded of articular cartilage. The undersurface of the acromion and the lateral aspect of the humerus are then decorticated, and a small wedge of bone is removed from the head to accommodate the acromion with its muscle pedicle at the desired position for arthrodesis, allowing the thumb to reach the chin when the elbow is flexed. This position is usually 20 to $30^{\circ}$ of abduction, $30^{\circ}$ of flexion and 45 to $50^{\circ}$ of internal rotation at the shoulder (Fig. 1b). For patients with injuries to the brachial plexus the arm was positioned in 80 to $90^{\circ}$ of abduction.

With the shoulder positioned a drill hole $(3.2 \mathrm{~mm})$ is made from the dorsal surface of the spine of the scapula through the humeral head into the medullary canal. A Rush pin $(5$ to $7 \mathrm{~mm})$ is introduced through this hole and tensionband cerclage between the body of the acromion and the neck of the humerus is used to press the graft into position (Fig. 1c).

Before the operation a shoulder spica cast is made in two parts, one extending from just below the nipples to the iliac crest, and the other to fit the arm with the elbow flexed to $90^{\circ}$. At the end of the operation these are joined with wooden struts which allow access to the wound. Movement of the elbow and wrist is allowed after four to six weeks but external support of the shoulder is maintained until radiological union is demonstrated at eight to ten weeks.

\section{Results}

The mean follow-up was 3 years ( 2 to 3.5 ). The mean time spent in hospital was one week.

All patients were pleased with the improvement in stability of the arm, the restoration of elbow function and improved control of the hand (Figs 2 and 3). Four of the 18 patients had some pain or discomfort, despite solid arthrodeses. All had been placed in more than $80^{\circ}$ of glenohumeral abduction which may have placed too much stress on the thoracoscapular musculature. These symptoms gradually settled as function improved. Ten patients found it difficult to sleep on the affected side because the forced adduction of the arm stressed the thoracoscapular musculature.

All but one patient achieved bony union within eight to 


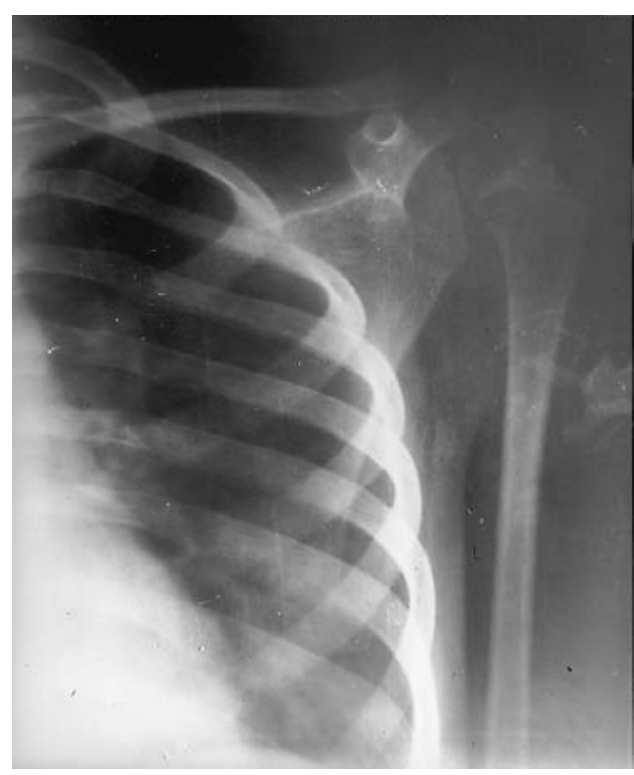

Fig. 2a

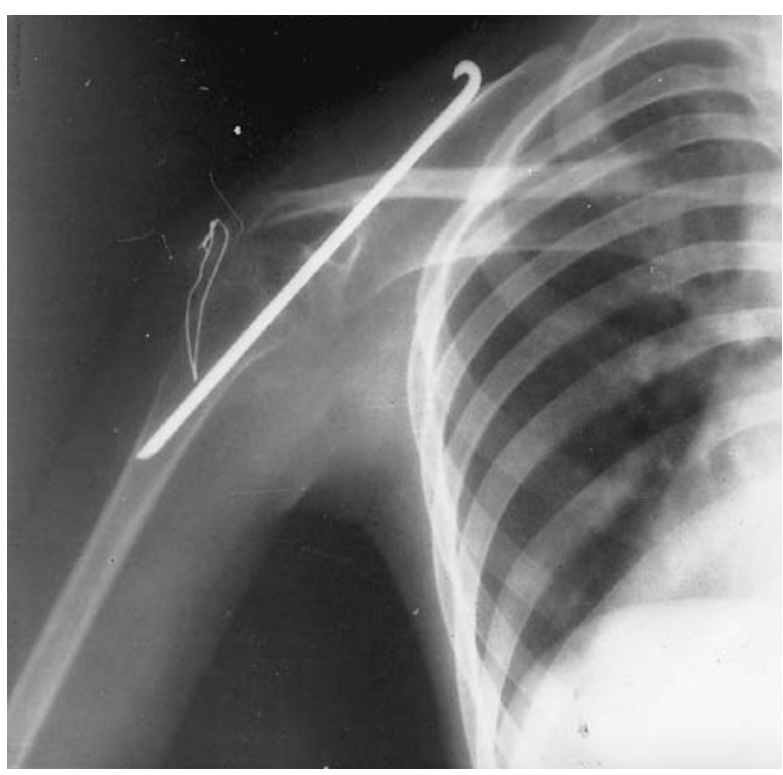

Fig. $2 b$

Radiographs of a 20-year-old man showing a) subluxation of the shoulder before operation and b) solid arthrodesis after operation at both glenohumeral and acromiohumeral sites.

ten weeks. The failure was in a woman, revised after a previous attempt at arthrodesis by another method. She was emotionally unstable and had twice removed her cast prematurely.

Apart from the failure, all patients could easily reach their face, rear trousers pocket, perineum and feet. The four patients with lesions of the brachial plexus had weak flexion of the elbow, but good scapulothoracic muscles, and had arthrodesis in 80 to $90^{\circ}$ of abduction to allow easier

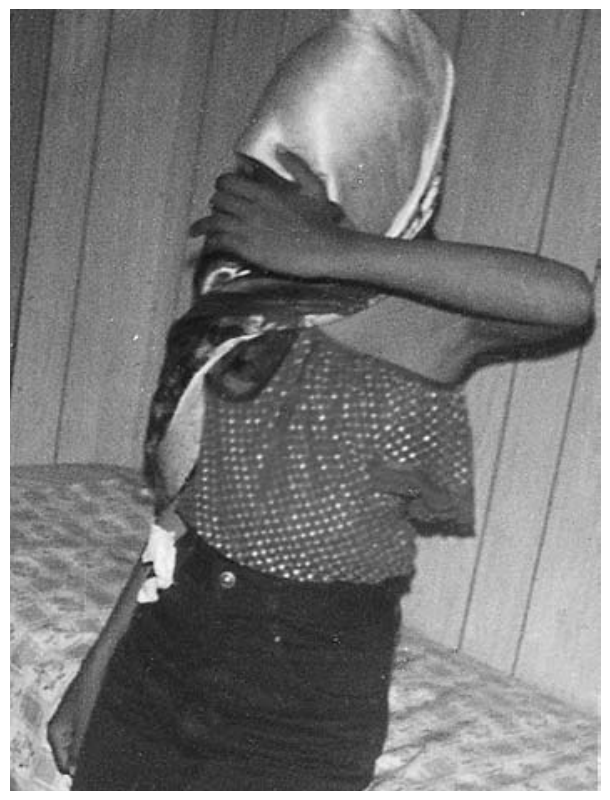

Fig. 3

Photograph showing improved stability, restoration of elbow function and improved control of the hand. elbow flexion, but this resulted in discomfort in the supporting muscles, as discussed above, and difficulty in reaching the back or buttocks. When the arm was at the side, there was prominent winging of the scapula, even more marked in the four patients fused in 80 to $90^{\circ}$ of abduction.

Complications. The Rush pin penetrated the cortex of the humerus in one patient but this did not affect the stability or healing of the arthrodesis. Two patients had wound infections which settled with aggressive dressing and antibiotics. One patient, aged 54 years, lost elbow movement for a period after immobilisation, but regained it with physiotherapy. One patient fell, sustaining an undisplaced fracture through the upper part of the humerus at the lower end of the Rush pin. This fracture healed after several weeks in a spica.

\section{Discussion}

A successful shoulder arthrodesis continues to offer satisfactory treatment for a wide selection of indications. ${ }^{7}$ A prosthesis with poor soft-tissue balance with muscle paralysis or atrophy is unstable and of little functional use. ${ }^{1}$ Tendon transfers depend on the condition of the articular surfaces of the shoulder, the occupation of the patient and the level of function required. Strength and stability can be provided only by multiple transfers to replace both prime movers and stabilisers and provide acceptable power, ${ }^{10,11}$ and it is difficult to obtain satisfactory gliding of tendon transfers around the shoulder. ${ }^{11}$ Arthrodesis places the arm in a stable functional position, and subsequent tendon transfers can improve movement and power in the elbow and also hand function. 
The shoulder is a difficult joint to fuse $^{6}$ because the humerus has a long lever arm, the area of contact at the glenohumeral joint is small and paralysed muscles cannot contribute compressive forces. 7,12

The optimum position for arthrodesis of the shoulder is debateable ${ }^{610}$ and the recommended positions have varied from 15 to $90^{\circ}$ of abduction, 15 to $45^{\circ}$ of flexion, and 15 to $50^{\circ}$ of internal rotation. ${ }^{2,13,14}$ Hawkins and Neer ${ }^{15}$ found rotation to be the most critical factor in influencing optimum function, but Cofield and Briggs ${ }^{16}$ reviewing 71 arthrodesed shoulders, concluded that the position of fusion had little effect on the result. Barr et $\mathrm{al}^{2}$ measured abduction from the vertebral border of the scapula, but Rowe ${ }^{13}$ used the side of the body as the reference plane and recommended abduction of 20 to $25^{\circ}$, flexion of $30^{\circ}$, and internal rotation of 45 to $50^{\circ}$. Patients with weak elbow flexors but good scapulothoracic muscles were arthrodesed at 80 to $90^{\circ}$ of abduction to assist elbow flexion, and we have followed these principles.

Many techniques for shoulder arthrodesis have been described. Casts and splints alone fail to provide reliable control of scapulohumeral movement. ${ }^{7,15}$ In 1964, Charnley and Houston ${ }^{17}$ introduced the compression principle for arthrodesis of the shoulder and claimed rapid union. A similar method using two pins between the acromion and the humeral head, supplemented by a figure-of-eight wire, was developed by Blauth and Hepp. ${ }^{18}$ De Velasco Polo and Cardoso Monterrubio ${ }^{14}$ used a Steinmann pin for fixation in children, but had six pseudarthroses in 31 shoulders after

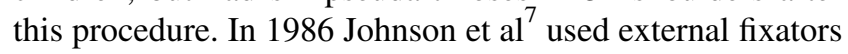
to allow earlier postoperative use of the arm and hand.

Kurakawa and Nagana ${ }^{19}$ report the use of a circular external fixator in seven patients after injuries to the brachial plexus. They had no significant problems and achieved adequate union at 85 to 105 days. External fixation, however, has its own complications due to neurovascular injury, pin-track infection, pin loosening and fractures through pin sites, but is particularly useful for infected joints. The AO technique to secure rigid internal fixation has given good results, ${ }^{3,10}$ but carries the risk of increased devascularisation and occasional problems from prominent screws, or loosening in osteoporotic bone.

Fixation by a Rush pin and tension-band cerclage provides good shear control and low axial stiffness. Unlike conventional rigid fixation it maintains axial elasticity which may accelerate union. It does not affect the growth plate of the proximal humerus in children, can be used in the presence of osteoporosis, and has a high rate of fusion.

No benefits in any form have been received or will be received from a commercial party related directly or indirectly to the subject of this article.

\section{References}

1. Rowe CR. Arthrodesis of the shoulder used in treating painful conditions. Clin Orthop 1983;173:92-6.

2. Barr JS, Freiberg JA, Colonna PC, Pamberton PA. A survey of end results on stabilisation of the paralytic shoulder. J Bone Joint Surg 1942; 24:699-707.

3. Kostuik JP, Schatzker J. Shoulder arthrodesis - A.O. technique. In: Bateman JE, Welsh RP, eds. Surgery of the shoulder. St. Louis, etc: CV Mosby Co, 1984:207-10.

4. Asirvatham R, Watts HG, Rooney RJ. Rotation osteotomy of the tibia after poliomyelitis: a review of 51 patients. J Bone Joint Surg [Br] 1990;72-B:409-11.

5. Justis EJ. Arthrodesis of shoulder, elbow and wrist. In: Crenshaw AH, ed. Campbell's operative orthopaedics. St Louis: Mosby Year Book, 1992:353-68.

6. Cofield RH. Arthrodesis and resectional arthroplasty of the shoulder. In: Evarts CM, ed. Surgery of the musculoskeletal system. New York, etc: Churchill Livingstone Inc, 1983:109-24.

7. Johnson CA, Healy WL, Brooker AF, Krackow KA. External fixation shoulder arthrodesis. Clin Orthop 1986;211:219-23.

8. Arntz CT, Jackins S, Matsen FA III. Prosthetic replacement of the shoulder for the treatment of defects in the rotator cuff and the surface of the glenohumeral joint. J Bone Joint Surg [Am] 1993;75-A: 485-91.

9. Seddon HJ. Transplantation of the pectoralis major muscle for paralysis of the flexors of the elbow. Proc Roy Soc Med 1949; $42: 837-8$.

10. Richards RR, Waddell JP, Hudson AR. Shoulder arthrodesis for the treatment of brachial plexus palsy. Clin Orthop 1985;198:250-8.

11. Leffert RD. Reconstruction of the shoulder and elbow following brachial plexus injury. In: Omer GE, Spinner M, eds. Management of peripheral nerve problems. Philadelphia: W. B. Saunders, 1980:805.

12. Beltran JE, Trilla JC, Barjau R. A simplified compression arthrodesis of the shoulder. J Bone Joint Surg [Am] 1975;57-A:538-41.

13. Rowe CR. Re-evaluation of the position of the arm in arthrodesis of the shoulder in the adult. J Bone Joint Surg [Am] 1974;56-A: 913-22.

14. De Velasco Polo G, Cardoso Monterrubio A. Arthrodesis of the shoulder. Clin Orthop 1973;90:178.

15. Hawkins RJ, Neer CS II. Functional analysis of the shoulder fusion. Clin Orthop 1987;223:65-76.

16. Cofield RH, Briggs BL. Glenohumeral arthrodesis: operative and long-term functional results. J Bone Joint Surg [Am] 1979;61-A: 668-77.

17. Charnley J, Houston JK. Compression arthrodesis of the shoulder. J Bone Joint Surg [Br] 1964;46-B:614-20.

18. Blauth W, Hepp WR. Arthrodesis of the shoulder joint by traction absorping wiring. In: Chapchal G, ed. The arthrodesis in the restoration of working ability. Stuttgart: Georg Thieme, 1975:30.

19. Kurokawa T, Nagano A. Shoulder arthrodesis. In: Coombs R, Green S, Sarmiento A, eds. External fixation and functional bracing. London, etc: Orthotext, 1989:173-5. 